This document is the accepted manuscript version of the following article:

Achermann, S., Falås, P., Joss, A., Mansfeldt, C., Men, Y., Vogler, B., \& Fenner, K. (2018). Trends in micropollutant biotransformation along a solids retention time gradient. Environmental Science and Technology. https://doi.org/10.1021/ acs.est. $8 \mathrm{~b} 02763$

\title{
Trends in micropollutant biotransformation along a solids retention time gradient
}

Stefan Achermann, ${ }^{1,2}$ Per Falås, ${ }^{1,3}$ Adriano Joss, ${ }^{1}$ Cresten B. Mansfeldt, ${ }^{1}$ Yujie Men, ${ }^{1,4}$ Bernadette Vogler, ${ }^{1}$ Kathrin Fenner*,1,2,5

${ }^{1}$ Eawag, Swiss Federal Institute of Aquatic Science and Technology, 8600 Dübendorf, Switzerland.

${ }^{2}$ Institute of Biogeochemistry and Pollutant Dynamics, ETH Zürich, 8092 Zürich, Switzerland.

${ }^{3}$ Department of Chemical Engineering, Lund University, 22100 Lund, Sweden. ${ }^{4}$ Department of Civil and Environmental Engineering, University of Illinois at Urbana-Champaign, Urbana, IL 61801, USA.

${ }^{5}$ Department of Chemistry, University of Zürich, 8057 Zürich, Switzerland.

*Corresponding author (email: kathrin.fenner@eawag.ch )

\section{Word count:}

Words: 6169

Table: 600 words

Figures: $300+600$ words

Total: 7669 words 


\section{Abstract}

2 For many polar organic micropollutants, biotransformation by activated sludge microorganisms is a

3 major removal process during wastewater treatment. However, our current understanding of how

4 wastewater treatment operations influence microbial communities and their micropollutant

5 biotransformation potential is limited, leaving major parts of observed variability in biotransformation

6 rates across treatment facilities unexplained. Here, we present biotransformation rate constants for 42

7 micropollutants belonging to different chemical classes along a gradient of solids retention time

8 (SRT). The geometric mean of biomass-normalized first-order rate constants shows a clear increase

9 between $3 \mathrm{~d}$ and $15 \mathrm{~d}$ SRT by $160 \%$ and $87 \%$, respectively, in two experiments. However, individual

10 micropollutants show a variety of trends. Rate constants of oxidative biotransformation reactions

11 mostly increased with SRT. Yet, nitrifying activity could be excluded as primary driver. For

12 substances undergoing other than oxidative reactions, i.e. mostly substitution-type reactions, more

13 diverse dependencies on SRT were observed. Most remarkably, characteristic trends were observed

14 for groups of substances undergoing similar types of initial transformation reaction, suggesting that

15 shared enzymes or enzyme systems that are conjointly regulated catalyze biotransformation reactions

16 within such groups. These findings open up opportunities for correlating rate constants with measures

17 of enzyme abundance, which in turn should help to identify genes or gene products associated with the

18 respective biotransformation reactions.

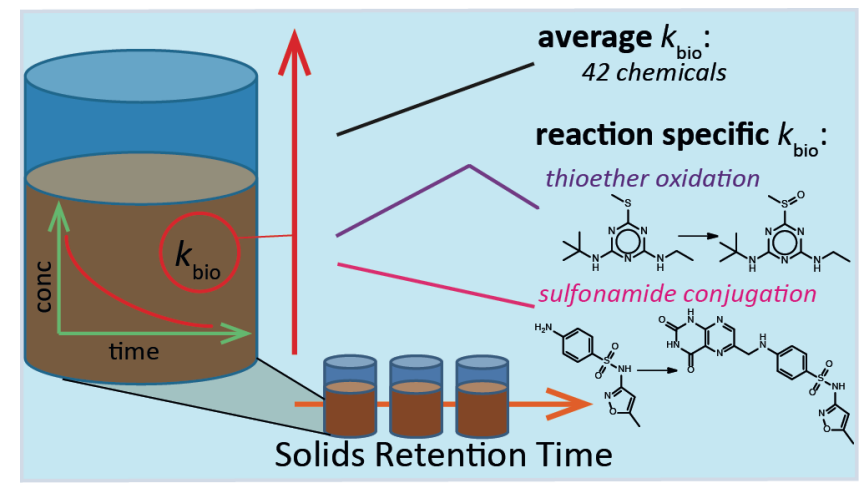




\section{Introduction}

To assess and minimize the risks imposed by the release of anthropogenic chemicals into the environment, understanding which factors determine transport and degradation processes of chemicals at the end of their product life-cycle is important. Pharmaceuticals and other domestic and industrial chemicals are frequently detected in wastewater. ${ }^{1}$ Although activated sludge-based treatments are primarily optimized to reduce biological oxygen demand (BOD) and nutrients such as ammonium and phosphorous, they also remove micropollutants (MPs) to varying degrees. In fact, for many polar, organic micropollutants, biotransformation by activated sludge microorganisms is an important removal process. ${ }^{1}$ Numerous attempts have been made to understand the influence of the molecular structure, process-related parameters, properties of the wastewater or characteristics of the microbial communities on MP biotransformation..$^{2-8}$ Although previous work shed light on the importance of various factors, a significant part of the observed variability in MP removal under different wastewater treatment conditions remains unexplained. ${ }^{9,}{ }^{10}$ Yet, a more thorough understanding of how observed variabilities in MP biotransformation rates and pathways, including formation of potentially hazardous transformation products (TP), depend on different influencing factors is of significant interest: It would enable more accurate predictions of biotransformation, which in turn would support chemical risk assessment, and it would open up opportunities to optimize treatment processes towards improved micropollutant removal.

Solids retention time (SRT), or sludge age, which defines the average time microbial biomass resides in a given treatment unit, has repeatedly been discussed as having a major influence on micropollutant biotransformation. In several studies, positive relationships between SRT and micropollutant removal have been reported ${ }^{1,11-26}$ and a beneficial effect of SRT on MP removal is widely accepted. ${ }^{27}$ Clara et $a l{ }^{12}$ first reported a strong correlation between effluent concentrations and SRT for bisphenol A, bezafibrate, ibuprofen and natural estrogens. Ternes and Joss observed that nitrifying wastewater treatment plants (WWTPs) operated at SRTs above $10 \mathrm{~d}$ removed MPs more efficiently than WWTPs operated at less than $4 \mathrm{~d} \mathrm{SRT}{ }^{1}$ However, in other studies, contrasting results were reported of no 
connection between MP removal and $\mathrm{SRT}^{10,19,28-33}$, or even higher removal at lower SRTs for certain MPs. ${ }^{28}$

To further understand these contradictory findings, there is a need to distinguish between overall removal of MPs and biomass-normalized (or biomass activity-normalized) biotransformation rate constants. As elaborated in Schwarzenbach et al., ${ }^{34}$ pseudo-first-order kinetics have frequently been observed for MP biotransformation in microbial communities, allowing to calculate biomassnormalized rate constants (often denoted $k_{\mathrm{bio}}$ ). ${ }^{1,35-37}$ At fixed reactor volumes and hydraulic retention times (HRTs), an increase in SRT leads to a higher concentration of active biomass. ${ }^{15}$ Even if biomass-normalized biotransformation rate constants were not affected by SRT, those higher biomass concentrations would most likely instigate a higher percentage of biological removal. ${ }^{22,38,39}$ A number of more recent studies describe attempts to better understand the influence of SRT on biotransformation rate constants. Petrie et al. have shown that estrogen biotransformation per bacterial cell was higher at $10 \mathrm{~d}$ than at $3 \mathrm{~d} \mathrm{SRT} \cdot{ }^{38}$ Falås et al. found higher VSS-normalized biotransformation rate constants for ketoprofen and naproxen in activated sludge from WWTPs operated at an SRT of at least $7 \mathrm{~d}$ compared to low SRTs of 1-3 d. ${ }^{23}$ In contrast, others reported that a decrease in SRT from 20 $\mathrm{d}$ to $5 \mathrm{~d}$ led to higher $k_{\mathrm{bio}}$ values for diclofenac, ibuprofen, naproxen and caffeine. ${ }^{32}$ Similarly, in a comparison of three activated sludge systems operated at SRTs of 3, 10 and $20 \mathrm{~d}$, the endocrine disrupting substances bisphenol A, triclosan and 4-n-nonylphenol showed highest $k_{\text {bio }}$ values at $3 \mathrm{~d}$ of SRT. ${ }^{19}$ Finally, no systematic influence of SRT on $k_{\text {bio }}$ for different MPs was observed for activated sludge reactors operated in parallel at high SRTs of 25, 40 and $80 \mathrm{~d}^{33}$

Taken together, previous observations remain restricted to a limited number of substances and do not allow for any general conclusions on the influence of SRT on MP biotransformation rates. It remains unclear which substance classes and types of biotransformation reactions are positively associated with SRT and through which mechanisms SRT affects biotransformation rates and pathways. Therefore, in this study, we aimed to address the question how MP biotransformation depends on SRT using MPs from different substance classes undergoing various types of biotransformation reactions. Specifically, we wanted to explore whether consistent trends would be found for classes of substances 
undergoing similar biotransformation reactions, and whether these trends could serve to generate hypotheses about underlying mechanisms. For this purpose, we established six bioreactors operated at a gradient of SRTs and designed a strategy to consistently profile the biotransformation potential of the cultivated activated sludge communities. The strategy included the selection of a diverse and sufficiently large set of MPs that were expected to undergo a range of oxidation and substitution reactions, and the establishment of an efficient workflow to study the biotransformation rate constants and reactions of the selected MPs.

\section{Methods}

\section{Reactor setup and operation}

For cultivation of activated sludge at different SRTs, six $12 \mathrm{~L}$ reactors were operated in parallel. The reactors were connected to a programmable logical controller (Wago 750-881) and a SCADA system (Citect V7.2, Schneider Electric), enabling automated operation as previously described. ${ }^{33}$ Online sensors allowed to control fill levels (Cerebar PMC131, Endress+Hauser) and dissolved oxygen (DO) concentrations (Oxymax COS61D, Endress+Hauser) and to monitor temperature (ISEmax CAS40D, Endress+Hauser). The reactors were equipped with feed pumps, discharge valves, flow-controlled fine-bubble aerators and stirrers. For inoculation of the reactors, activated sludge was collected from the nitrification tank of a full-scale WWTP receiving mostly municipal wastewater (WWTP Niederglatt, 40,000 population equivalents, details in the Supporting Information (SI), section S1). DO levels in the reactors were controlled within the range of $1.5-3 \mathrm{mg} / \mathrm{L}$ via intermittent aeration. The six reactors were operated as sequencing batch reactors (SBRs) at a fixed HRT (12 h) and different SRTs $(1,3,5,7,10$ and $15 \mathrm{~d})$. The reactors were operated in fully-automated $4 \mathrm{~h}$ cycles comprising a settling phase, a discharge phase, a feed phase and a reaction phase as detailed in the SI (section S1). For reactor feeding, municipal wastewater was collected after primary treatment (screening, grit removal, and sedimentation) from an urban catchment of 30,000 population equivalents. To adjust the SRTs, different portions of activated sludge were withdrawn from the six reactors according to Table S1. All total suspended solids (TSS) measurements performed prior to and during the 
biotransformation experiments showed gradually increasing values from the first to the sixth reactor, confirming a gradual increase in actual SRTs (SI section S2). The reactor temperatures varied slightly according to the temperature in the sewer $\left(18 \pm 2{ }^{\circ} \mathrm{C}\right)$.

\section{Biotransformation profiling strategy and workflow}

Our strategy to profile the biotransformation potential of the activated sludge communities is summarized in the following. More details are given in the SI, Sections S2-S7.

\section{Selection of chemicals}

Multiple substances covering the same chemical class and for which we expected similar initial biotransformation reactions according to molecular structure-based in silico pathway prediction using the EAWAG pathway prediction system (EAWAG-PPS, http://eawag-bbd.ethz.ch/predict/) and reported pathways from literature were included. For instance, for primary amides, nitriles or carboxylic esters, hydrolysis reactions were expected, whereas oxidative demethylation reactions were expected for phenylureas or generally for tertiary amides. Chemicals of known environmental relevance were additionally included, resulting in a total of 93 analyzed chemicals (for further details on chemicals and expected transformation reactions, see section S3).

\section{Biotransformation experiments}

Biotransformation batch experiments were started after 48 days (Exp1) and 187 days (Exp2) of reactor operation with a total of 77 (Exp1) and 93 (Exp2) chemicals, respectively. In Exp1, the experiment was conducted in the $12 \mathrm{~L}$ SBRs directly where, for the duration of the batch experiment, the cycling was paused after a feed phase. In Exp2, the activated sludge was transferred to smaller glass bottles (100 mL, triplicates for each SRT) that were equipped with caps with two holes to maintain aerobic conditions and placed on a shaker table. MPs were spiked to final concentrations of $6 \mu \mathrm{g} / \mathrm{L}$ each in each reactor. Samples were collected at multiple time points over 3-4 days. The samples were centrifuged, and the supernatant was transferred to HPLC vials. A mix of isotope-labeled internal standard substances was added to account for losses and interferences during liquid chromatography coupled to high-resolution mass spectrometry (LC-HRMS) measurements, and the samples were stored at $4{ }^{\circ} \mathrm{C}$ for a maximum of 7 days until analysis. In the first 4 hours of each experiment, samples 
were collected for measuring concentrations of $\mathrm{NH}_{4}{ }^{+}, \mathrm{NO}_{2}{ }^{-}$and $\mathrm{NO}_{3}{ }^{-}$. $\mathrm{pH}$ was measured using a

127 HQ30d Flexi Meter (Hach Lange). In parallel to each biotransformation experiment, sorption and

128 abiotic control experiments were performed in triplicate in $100-\mathrm{mL}$ reactors according to Gulde et

$129 a l .{ }^{37}$ i.e., autoclaved filtrate (cellulose nitrate filter, $0.45 \mu \mathrm{m}$, Sartorius Stedim Biotech) and

130 autoclaved activated sludge were used to estimate the fractions that were abiotically degraded and

131 sorbed to activated sludge solids, respectively.

132 Additional experiments to investigate biotransformation under oxygen limited conditions (ExpOx) and

133 to support transformation product analysis (ExpTP) were started after 356 days and after 243 days of

134 reactor operation, respectively, both with activated sludge sampled from the reactor operated at $7 \mathrm{~d}$ of

135 SRT. In ExpOx, biotransformation under aerobic conditions (as in Exp1 and Exp2) was compared to

136 biotransformation in sealed bottles run under DO limitation. In these, the initially present electron-

137 accepting nitrogen species (nitrite and nitrate) were consumed in the first five hours, and anaerobic

138 conditions then prevailed until the end of the experiment. For further details on biotransformation

139 experiments see section S4.

140 Chemical analysis and evaluation of rate constants

141 Mass spectra were recorded on a QExactive Plus (Thermo Scientific) mass spectrometer. Full-scan

142 MS spectra were acquired in both positive and negative ionization modes and the acquisition of $\mathrm{MS}^{2}$

143 fragmentation spectra was triggered at $\mathrm{m} / \mathrm{z}$ values corresponding to masses of suspected transformation

144 products (see below). Details on chromatographic separation and mass spectrometric analysis are

145 provided in the SI (section S5). Calibration standards were prepared in nanopure water (Barnstead

146 Nanopure, Thermo Scientific) covering a concentration range between 0.05 and $10 \mu \mathrm{g} / \mathrm{L}$.

147 Target chemical concentrations were quantified with Tracefinder 3.1 (Thermo Scientific). From the

148 resulting concentration-time series, first-order biotransformation rate constants were derived in line

149 with the pseudo-first order assumption, which has proven useful to describe biotransformation of low

150 concentrated chemicals in cases where the enzymatic turnover of the substrate is rate-limiting (for

151 further discussion see Section S6). ${ }^{1,34}$ First-order rate constants were calculated by a censored linear

152 regression applied to the logarithmic concentrations against time, using the software R (Version: 3.3.0) 
and the command "censReg" from the package "censReg". Concentrations below 5\% of the initially spiked concentration (for which for some MPs no reasonable chromatographic peak (less the three full-scans) and deviation from first-order kinetics was observed) were treated as censored values. Chemicals selected for further analysis included those that (1) did not strongly adsorb $(<30 \%$ in the sorption experiments), (2) did not show abiotic degradation $(<20 \%$ at end of the abiotic control experiments) and (3) exhibited first-order kinetics (see Section S6 and Table S6, also for criteria for first-order kinetics). To study the effect of differences in microbial community composition across reactors containing different total biomass concentrations, first-order rate constants for these chemicals were converted into second-order rate constants by normalization with TSS. In doing so, uncertainties of the observed rate constants and TSS measurements were propagated using a Monte Carlo approach (R package "propagate"). Biases involved with using TSS as an approximation for active biomass are discussed in the SI (section S2). Because adsorption to activated sludge and abiotic losses were minor for the selected chemicals, their normalized rate constants are further denoted as second-order biotransformation rate constants, $k_{\text {bio. }}$ Finally, to enable comparisons of rate constants across all reactors, only chemicals were further considered for which $k_{\text {bio }}$ for at least one SRT was higher than a predefined threshold value (Exp1: $0.162 \operatorname{Lg}_{\mathrm{TSS}}{ }^{-1} \mathrm{~d}^{-1}$, Exp2: $0.121 \mathrm{Lg}_{\mathrm{TSS}}{ }^{-1} \mathrm{~d}^{-1}$ ) corresponding to approximately $30 \%$ removal over 2 days in the reactor with the lowest measured biomass concentration.

Trends of biotransformation rate constants with SRT were analyzed as follows: We calculated Spearman rank correlation coefficients $(\rho)$ between $k_{\text {bio }}$ and SRT by repeated $(\mathrm{n}=10,000)$ sampling of $k_{\text {bio }}$ values for each SRT from their distributions obtained from error propagation. We further compared trends with SRT across MPs by substance-wise auto-scaling and centering of $k_{\text {bio }}$ values

175 (Details on scaling in section S6). ${ }^{40}$ Heatmaps were produced using the R package "pheatmap" and 176 ordering of chemicals followed hierarchical clustering (using Euclidean distance and complete 177 linkages). For ExpOx, $k_{\text {bio }}$ values were obtained similarly as for Exp1 and Exp2 (see Table S10), and a 178 ratio between rate constants under anaerobic and aerobic conditions, further denoted $k_{\text {anaer }} / k_{\text {aer, }}$ was 179 calculated for each chemical. 
A suspect transformation product screening was performed using the software Compound Discoverer 2.0 (Thermo Scientific). After peak picking and pre-filtering (details in section S7), a subset of features was selected based on a comparison with a predefined suspect list. In addition to the TPs predicted by the Eawag-PPS or described in the literature, further potential TP masses were calculated considering mass shifts of common biotransformation reactions (hydroxylation, dihydroxylation, demethylation, dehydrogenation, hydrogenation and decarboxylation). To facilitate structure elucidation and assessment of the parent-TP relationships, an auxiliary experiment (ExpTP) was performed in which the micropollutants were spiked in groups of 10-20 chemicals and at higher concentrations ( $50 \mu \mathrm{g} / \mathrm{L}$ each). If for detected features with exact masses contained in the suspect list a reasonable peak area-time trend (either increasing or first in- and then decreasing) was observed in MS spectra from Exp2 and the TP was only detected in samples from batches spiked with the respective parent MP in ExpTP, MS ${ }^{2}$ fragmentation spectra were analyzed (further details in section S7) unless the TP could be confirmed by comparing the retention time with an authentic reference standard (Table S11).

TP evidence, i.e., observed changes in molecular formula and structure, was then used to assign corresponding reaction types to the parent MPs. This approach involved varying degrees of uncertainty because for most TPs their relative importance could not be accurately quantified because of a lack of authentic standards. Also, despite having assembled a rather exhaustive TP suspect list, TPs might still have been missed in our analysis. However, in most cases, the TPs found were in good agreement with previously published pathways. Additionally, based on ratios of $k_{\text {anaer }} / k_{\text {aer }}$ observed for MPs with well-established transformation reactions (e.g., pargyline, valsartan and atenolol), we could

202 confirm our expectation that $k_{\text {anaer }} / k_{\text {aer }}$ ratios would generally be smaller for oxidative transformations 203 than for substitution-type reactions. These ratios were therefore used to support assignment of reaction types to MPs with less well-established transformation reactions. 


\section{Results and Discussion}

\section{Reactor operation}

After inoculation, the six parallel sequencing batch reactors were operated at SRTs of 1, 3, 5, 7, 10 and $15 \mathrm{~d}$ as described in the methods section. During the initial phase, TSS as well as influent and effluent concentrations of nitrogen species $\left(\mathrm{NH}_{4}{ }^{+}, \mathrm{NO}_{2}{ }^{-}, \mathrm{NO}_{3}{ }^{-}\right)$were measured on a regular basis (Tables $\mathrm{S} 2$ and S3). After 7 days of operation, TSS values had developed from initially $3.4 \mathrm{~g} / \mathrm{L}$ in all reactors to $0.2,1.3,1.7,2.0,2.9$ and $3.1 \mathrm{~g} / \mathrm{L}$ for SRTs of $1,3,5,7,10$ and $15 \mathrm{~d}$, respectively. The reactor at $1 \mathrm{~d}$ SRT had lost its nitrifying activity after 7 days while the reactors at 7, 10 and $15 \mathrm{~d}$ SRT remained nitrifying at all measured time points. Possibly caused by fluctuations in temperature ${ }^{40}$, conversion of ammonium to nitrate was also observed at 3 and $5 \mathrm{~d}$ of SRT in Exp2. Indeed, slightly higher mean temperatures were recorded in the two weeks before Exp2 (19.3 \pm 1.0$)$ compared to Exp1 (18.1 \pm 0.7$)$. Data on TSS, pH, temperature, nitrifying activity and oxygen uptake rates during Exp1 and Exp2 are provided in Tables S4 and S5.

\section{Dependence of biotransformation rate constants on SRT}

Of the initially selected MPs, a considerable number (Exp1: 20, Exp2: 16) was not degraded sufficiently to allow for a reliable determination and comparison of $k_{\text {bio }}$. In particular, the biotransformation of MPs with a triazine structure (for which halide substitution was predicted) and MPs predicted to undergo O-dealkylation or tertiary amide N-dealkylation were often only slowly transformed unless an alternative (faster) transformation pathway was possible (Table S6, for observed pathways see below). For a number of MPs, concentration-time curves deviated from an exponential decay insofar as the transformation seemed to stall after an initial decline in concentration. In agreement with the recently described trapping of amine-containing MPs in protozoa, ${ }^{42}$ this pattern was mainly observed for amine-containing MPs.

For the 33 (Exp1) and 42 (Exp2) substances selected for further analysis according to the criteria defined above, biomass-normalized rate constants $k_{\text {bio }}$ were calculated (Figure S3 and S4). The comparably low biomass concentration in the reactor at $1 \mathrm{~d}$ SRT $(0.43 \pm 0.03 \mathrm{~g} / \mathrm{L})$ in Exp1 led to low 
measured first-order rate constants with high relative errors (Figure S5). Therefore, this reactor was

232 not considered for further analyses. For both experiments, geometric mean $k_{\text {bio }}$ values across all

233 compounds were calculated for each SRT (Figure 1). An increasing trend of the mean $k_{\text {bio }}$ with SRT

234 was observed between SRTs of $3 \mathrm{~d}$ and $7 \mathrm{~d}(\operatorname{Exp} 1:+160 \%$, Exp2: $+87 \%)$, whereas mean $k_{\text {bio }}$ values at

2357,10 and $15 \mathrm{~d}$ SRT were rather similar. Considering that fractions of active biomass per total

236 suspended solids are expected to decrease with higher SRT ${ }^{15,35}$ (also see section S2), normalization by

237 TSS likely led to a slight underestimation of the overall increase in biotransformation efficiency per

238 active cell with SRT.

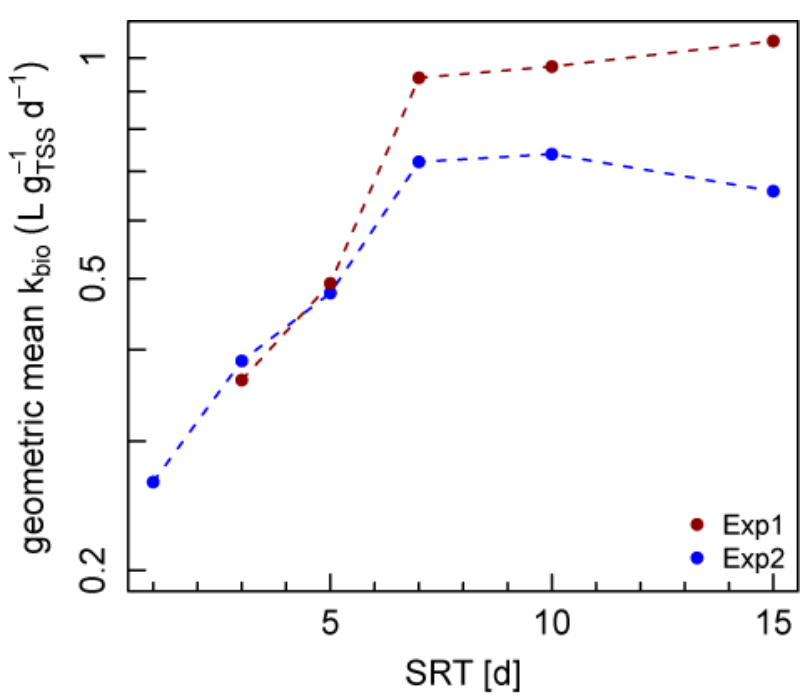

241 Figure 1: Geometric mean rate constants (logarithmic y-axis) obtained from Exp1 (33 MPs) and Exp2 242 (42 MPs) in dependence on the SRT.

243 When looking at trends of individual MPs instead of mean rate constant trends, we observed a remarkable variety of differing trends. In Figure 2, the scaled rate constants for the individual MPs in both Exp1 and Exp2 are presented as a clustered heatmap. Additionally, the heatmap is annotated with information on the ratio $k_{\max } / k_{\min }$ between the lowest and the highest rate constant observed between 3 $\mathrm{d}$ and $15 \mathrm{~d}$ SRT. $k_{\max } / k_{\min }$ ratios close to 1 indicate that the microbial communities are similarly efficient in biotransformation of the respective substance at different SRTs, whereas high $k_{\max } / k_{\min }$ ratios indicate that changes in the microbial communities along the SRT gradient strongly affect the respective transformation. 

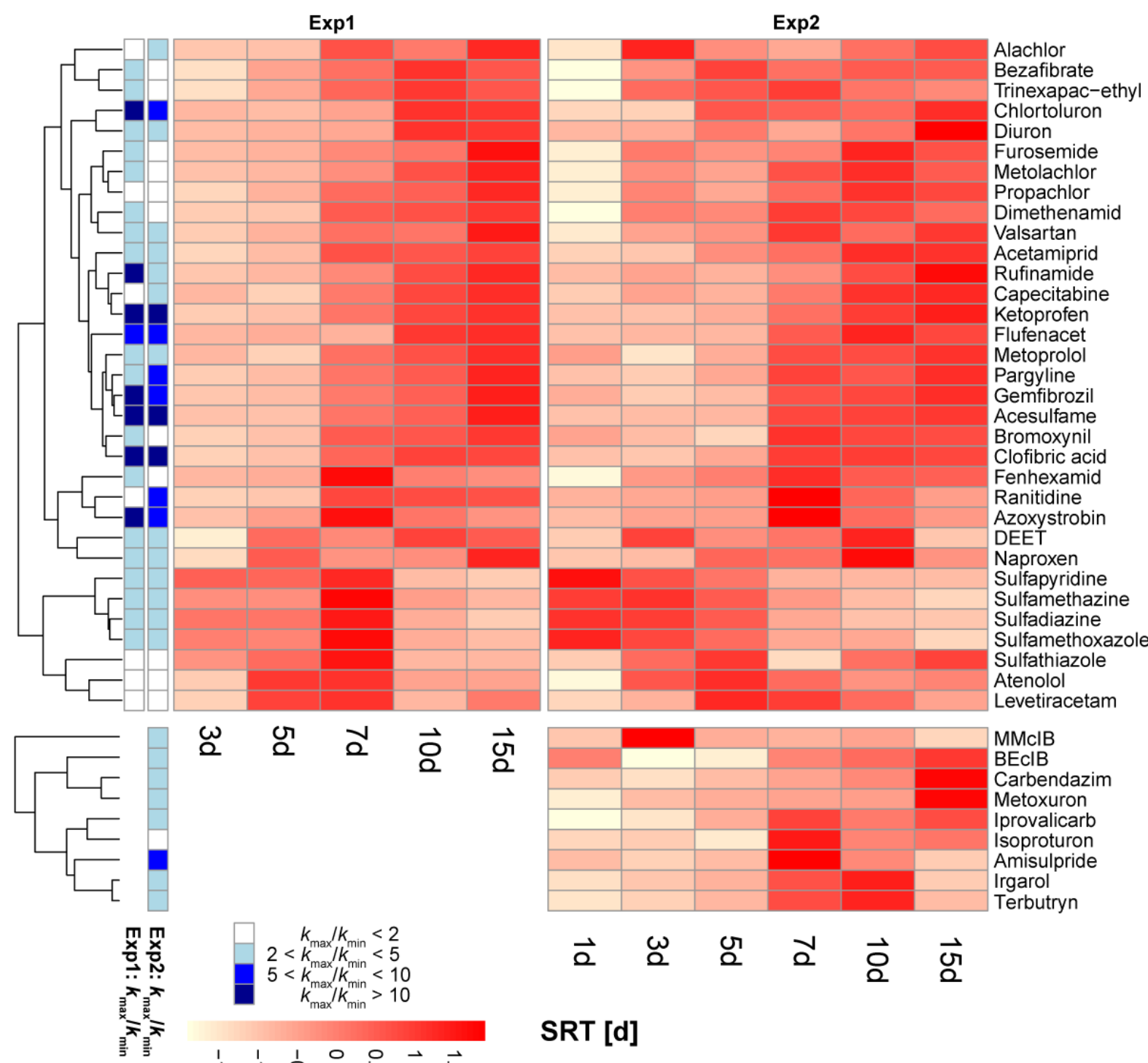

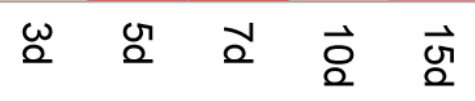
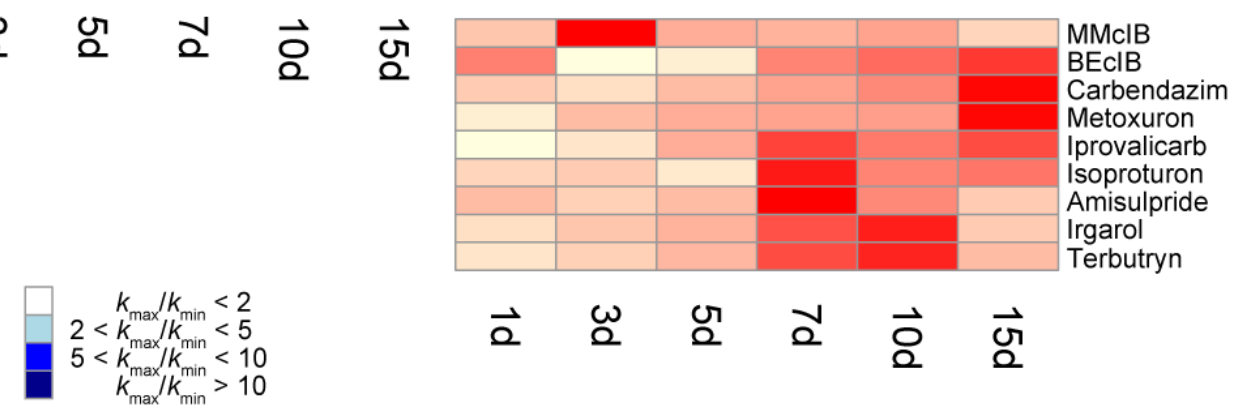

\section{SRT [d]}

Figure 2: Substance-wise auto-scaled rate constants from Exp1 (33 MPs) and Exp2 (42 MPs) (see SI section S6 for details). Levels of relative differences in $k_{\text {bio }}$ between 15 and $3 \mathrm{~d}$ of SRT are annotated on the left. Ordering of MPs followed hierarchical clustering of the combined trends obtained in Exp1 and Exp2 (33 MPs) and, separately, for the 9 MPs additionally investigated in Exp2.

256 The trends shown in Figure 2 confirm that the majority of micropollutants feature increasing

257 degradation with increasing SRTs. However, for individual substances, different trends can be

258 observed. Although some MPs roughly follow the trend of the geometric mean presented in Figure 1,

259 many showed highest rate constants only at the highest SRTs of $10 \mathrm{~d}$ or $15 \mathrm{~d}$. Also, opposite trends

260 with lowest rate constants at highest SRTs or highest rate constants (e.g., for the sulfonamides) at

261 intermediate SRTs (e.g., for ranitidine, azoxystrobin, DEET or naproxen) were observed. Yet, the

262 generally similar trends across Exp1 and Exp2 demonstrate that biotransformation rate constants of 
263 various MPs show systematic trends with SRT and that these trends are reproducible at different time

264 points after start of the reactor operation and across different experimental settings (12 L bioreactors in

265 Exp1 versus $100 \mathrm{~mL}$ bioreactors in Exp2).

\section{Substance class- and reaction type-specific trends}

267 The diversity of observed trends suggests that the different microbial species and enzymes responsible

268 for the biotransformation of individual substances depend differently on SRT. Therefore, we

269 hypothesized that clustering of trends could potentially be indicative of interactions of a specific

270 (group of) enzyme(s) with similar functional moieties of different MPs. To investigate this hypothesis,

271 we compared trends within and amongst different classes of substances and reaction types as

272 characterized based on observed transformation products and additional information, e.g., $k_{\text {anaer }} / k_{\text {aer }}$.

273 (Table 1). 


\begin{tabular}{|c|c|c|c|c|c|c|c|c|c|}
\hline 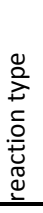 & $\begin{array}{c}\stackrel{\Xi}{\varepsilon} \\
\stackrel{0}{c} \\
\end{array}$ & 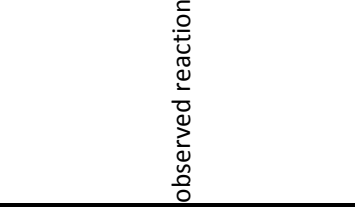 & 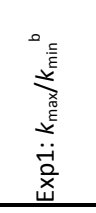 & 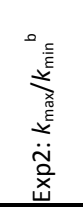 & $\begin{array}{l}\stackrel{0}{\vec{a}} \\
\stackrel{\vec{x}}{\stackrel{x}{a}} \\
a\end{array}$ & 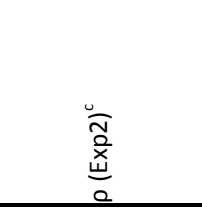 & 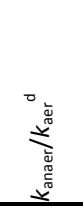 & 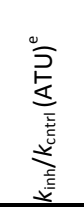 & 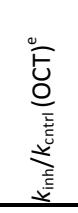 \\
\hline \multirow{17}{*}{ 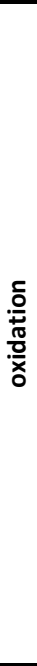 } & Chlortoluron & dealk./dihydrox./hydrox. & $>3.36$ & 6.48 & $0.9(0.8-1.0)$ & $0.6(0.6-0.9)$ & $<0.08$ & 0.16 & 0.73 \\
\hline & Diuron & dealk. ${ }^{43} /$ dihydrox. & 3.20 & 3.34 & $0.9(0.6-1.0)$ & $0.7(0.5-0.9)$ & $<0.14$ & 0.27 & 0.60 \\
\hline & Isoproturon & dealk. ${ }^{10} /$ hydrox. & $n / a$ & 1.75 & $\mathrm{n} / \mathrm{a}$ & $0.6(-0.1-0.7)$ & $<0.13$ & 0.55 & 0.58 \\
\hline & Metoxuron & dealk./dihydrox. & $\mathrm{n} / \mathrm{a}$ & 2.74 & $\mathrm{n} / \mathrm{a}$ & $0.9(0.2-1.0)$ & 0.36 & $<0.80$ & $<0.80$ \\
\hline & Irgarol & S-oxidation ${ }^{44}$ & $n / a$ & 3.36 & $\mathrm{n} / \mathrm{a}$ & $0.0(-0.1-0.7)$ & $<0.16$ & 0.45 & 0.68 \\
\hline & Ranitidine & S-oxidation ${ }^{\mathrm{f}, 45}, \mathrm{~N}$-oxidation ${ }^{45}$ & 1.65 & 6.00 & $0.7(0.5-1.0)$ & $0.6(0.3-0.6)$ & 0.32 & 0.22 & 0.70 \\
\hline & Terbutryn & S-oxidation ${ }^{44}$ & $\mathrm{n} / \mathrm{a}$ & 4.82 & $\mathrm{n} / \mathrm{a}$ & $0.4(0.0-0.7)$ & $<0.13$ & 0.38 & 0.74 \\
\hline & Valsartan & amide dealk. ${ }^{36}$ & 3.69 & 2.11 & $0.9(0.7-1.0)$ & $0.8(0.6-0.9)$ & 0.04 & 0.90 & 0.64 \\
\hline & $\mathrm{BEclB}$ & amide dealk./hydrox. ${ }^{36}$ & $\mathrm{n} / \mathrm{a}$ & 2.50 & $\mathrm{n} / \mathrm{a}$ & $1.0(0.8-1.0)$ & $<0.14$ & 0.77 & 0.43 \\
\hline & MMclB & amide dealk. ${ }^{36}$ & $\mathrm{n} / \mathrm{a}$ & 2.68 & $\mathrm{n} / \mathrm{a}$ & $-0.7(-1.0--0.2)$ & $<0.35$ & 0.72 & $<0.25$ \\
\hline & Furosemid & amine dealk. & 4.78 & 1.72 & $1.0(0.9-1.0)$ & $0.6(0.2-0.9)$ & $<0.10$ & 0.14 & 0.54 \\
\hline & Amisulpride & $\mathrm{N}$-oxidation/amine dealk. & $\mathrm{n} / \mathrm{a}$ & 7.99 & $\mathrm{n} / \mathrm{a}$ & $0.3(-0.2-0.6)$ & $<0.34$ & 0.51 & 0.98 \\
\hline & Pargyline & $\mathrm{N}$-oxidation ${ }^{42}$ & 3.54 & 5.38 & $0.9(0.6-1.0)$ & $0.9(0.6-1.0)$ & 0.05 & 0.29 & 0.55 \\
\hline & Ketoprofen & hydrox./biphenyl pathway ${ }^{46}$ & 19.47 & 17.06 & $1.0(0.9-1.0)$ & $1.0(1.0-1.0)$ & $<0.01$ & 0.71 & 0.89 \\
\hline & Gemfibrozil & hydrox. ${ }^{47}$ & 14.21 & 6.60 & $1.0(0.9-1.0)$ & $1.0(0.8-1.0)$ & $<0.01$ & 0.94 & 0.74 \\
\hline & Clofibric acid & hydrox. & $>11.60$ & 10.17 & $0.9(0.9-1.0)$ & $0.7(0.6-1.0)$ & 0.08 & 0.33 & 0.50 \\
\hline & Iprovalicarb & hydrox. & $\mathrm{n} / \mathrm{a}$ & 3.15 & $\mathrm{n} / \mathrm{a}$ & $0.7(0.7-0.9)$ & 0.18 & 0.79 & 0.93 \\
\hline \multirow{2}{*}{ 용 } & Capecitabine & hydrox./hydrolysis & 1.75 & 2.02 & $0.9(0.8-0.9)$ & $0.9(0.7-1.0)$ & 0.09 & 0.33 & 0.30 \\
\hline & Bezafibrate & amide dealk./hydrolysis $^{48}$ & 3.05 & 1.62 & $0.9(0.7-1.0)$ & $0.4(0.1-0.8)$ & 0.03 & 0.49 & 0.52 \\
\hline \multirow{18}{*}{ 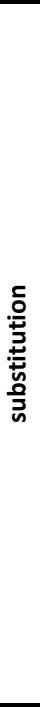 } & Levetiracetam & amide hydrolysis $^{48}$ & 1.37 & 1.98 & $0.1(-0.6-0.7)$ & $0.0(-0.4-0.1)$ & 0.06 & 0.70 & 0.71 \\
\hline & Atenolol & amide hydrolysis $^{10}$ & 1.66 & 1.66 & $0.1(0.0-0.2)$ & $-0.8(-0.9--0.2)$ & 1.97 & 1.21 & 1.09 \\
\hline & Rufinamide & amide hydrolysis & 15.84 & 4.54 & $1.0(1.0-1.0)$ & $0.9(0.9-0.9)$ & 0.37 & 0.65 & 0.87 \\
\hline & Dimethenamid & substitution/reduction ${ }^{\mathrm{g}}$ & 2.07 & 1.21 & $1.0(0.8-1.0)$ & $0.5(-0.5-0.9)$ & 0.70 & 0.88 & 0.91 \\
\hline & Alachlor & substitution/reduction ${ }^{\mathrm{g}}$ & 1.65 & 2.23 & $0.9(0.8-0.9)$ & $-0.1(-0.2-0.3)$ & 0.67 & 0.95 & 0.98 \\
\hline & Flufenacet & substitution/reduction $^{\mathrm{g}}$ & 5.96 & 5.38 & $0.9(0.8-0.9)$ & $0.8(0.8-0.9)$ & 0.72 & 0.77 & 0.81 \\
\hline & Propachlor & substitution ${ }^{10} /$ reduction $^{\mathrm{g}}$ & 1.99 & 1.54 & $1.0(0.9-1.0)$ & $0.8(0.2-1.0)$ & 0.92 & 0.90 & 0.88 \\
\hline & Metolachlor & substitution/reduction ${ }^{\mathrm{g}} /$ dealk. & 2.32 & 1.28 & $1.0(0.9-1.0)$ & $0.6(-0.3-1.0)$ & 0.75 & 0.89 & 0.87 \\
\hline & Sulfamethazine & pterin-conjugation $^{49}$ & 2.99 & 2.57 & $-0.6(-0.7--0.3)$ & $-1.0(-1.0--0.9)$ & 0.43 & 1.09 & 1.05 \\
\hline & Sulfapyridine & pterin-conjugation ${ }^{49}$ & 3.83 & 3.16 & $-0.7(-0.7--0.6)$ & $-1.0(-1.0--0.7)$ & 0.63 & 1.18 & 1.04 \\
\hline & Sulfadiazine & pterin-conjugation ${ }^{49}$ & 2.57 & 2.26 & $-0.6(-0.7--0.6)$ & $-0.9(-1.0--0.7)$ & 0.65 & 1.11 & 1.03 \\
\hline & Sulfamethoxazole & pterin-conjugation $^{49}$ & 2.89 & 2.65 & $-0.7(-0.7--0.5)$ & $-0.9(-1.0--0.8)$ & 0.89 & 1.20 & 1.10 \\
\hline & Sulfathiazole & pterin-conjugation ${ }^{49}$ & 1.56 & 1.28 & $-0.5(-0.7-0.2)$ & $0.1(-0.7-0.8)$ & 0.61 & 0.74 & 0.88 \\
\hline & Azoxystrobin & ester hydrolysis ${ }^{10}$ & 22.91 & 6.74 & $0.6(0.6-0.6)$ & $0.6(0.1-0.6)$ & 0.38 & 0.91 & 0.84 \\
\hline & Trinexapac-ethyl & ester hydrolysis ${ }^{10}$ & 2.27 & 1.38 & $0.9(0.7-0.9)$ & $-0.5(-0.9-0.3)$ & 0.36 & 0.80 & 1.07 \\
\hline & Bromoxynil & nitrile hydration & 3.61 & 1.52 & $1.0(0.8-1.0)$ & $0.6(0.2-0.9)$ & 0.62 & 0.62 & 0.92 \\
\hline & Acetamiprid & nitrile hydration & 3.77 & 3.43 & $0.9(0.7-1.0)$ & $0.9(0.9-1.0)$ & 0.24 & 0.50 & 0.39 \\
\hline & Carbendazim & carbamate hydrolysis ${ }^{45}$ & $\mathrm{n} / \mathrm{a}$ & 3.30 & $\mathrm{n} / \mathrm{a}$ & $1.0(0.8-1.0)$ & 0.19 & $<0.48$ & 0.84 \\
\hline \multirow{5}{*}{ 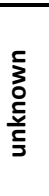 } & Acesulfame & $n / a^{h}$ & 74.02 & 23.67 & $1.0(0.9-1.0)$ & $0.9(0.6-1.0)$ & 0.08 & 0.97 & 1.08 \\
\hline & Metoprolol & $n / a^{i}$ & 2.32 & 2.67 & $0.9(0.6-0.9)$ & $0.9(0.6-1.0)$ & $<0.02$ & $\mathrm{n} / \mathrm{a}$ & $\mathrm{n} / \mathrm{a}$ \\
\hline & DEET & $n / a^{h}$ & 2.48 & 2.47 & $0.8(0.4-0.9)$ & $-0.3(-0.6--0.1)$ & 0.02 & 0.92 & 0.97 \\
\hline & Naproxen & $n / a^{h}$ & 2.53 & 3.96 & $0.7(0.3-0.7)$ & $0.3(0.3-0.4)$ & 0.02 & 1.03 & 1.04 \\
\hline & Fenhexamid & $n / a^{h}$ & 3.06 & 1.66 & $0.6(0.3-0.7)$ & $0.6(0.3-0.7)$ & 0.28 & 0.41 & 0.66 \\
\hline
\end{tabular}

${ }^{\mathrm{a}}$ Observed reactions (for details see methods and SI, section S7). Dealk. indicates dealkylation, hydrox. indicates hydroxylation, dihydrox. indicates dihydroxylation. Citations refer to literature describing the same transformation in activated sludge or activated sludge-derived communities. ${ }^{b}$ Ratios of highest rate constants over lowest rate constants per substance within the range of SRTs between $3 \mathrm{~d}$ and $15 \mathrm{~d}$. For chlortoluron and clofibric acid in Exp1, the minimum rate constants were very low and set to $0.048 \mathrm{~L} /\left(\mathrm{g}_{\mathrm{Tss}} \times \mathrm{d}\right)$, corresponding to $10 \%$ removal over 2 days in the reactor operated at $1 \mathrm{~d}$ SRT. ${ }^{\text {'S Spearman rank }}$ correlation coefficients and empirical confidence intervals $(95 \%)$. ${ }^{d}$ Ratio of rate constants obtained under aerobic and anaerobic conditions (rate constants in Table S10). ${ }^{e}$ Ratio of rate constants (inhibited over control) using the ammonia monooxygenase inhibitors allylthiourea (ATU) and octyne (OCT). Data based on Men et al. ${ }^{50}$, rate constants are provided in Table S10. ${ }^{\mathrm{f}} \mathrm{Quantification}$ of $\mathrm{N}$ - and S-oxides indicated that S-oxidation represents the major reaction. ${ }^{9} \mathrm{For}$ the acetanilides, reductive

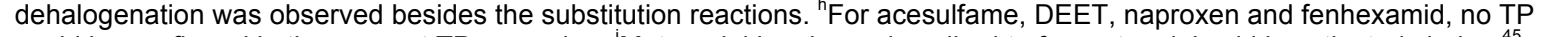
could be confirmed in the suspect TP screening. 'Metoprolol has been described to form atenolol acid in activated sludge. ${ }^{45}$ Since metoprolol was not spiked and was, therefore, present in lower concentrations than atenolol, potential minor contribution to the formation of atenolol acid from metoprolol remained elusive. 
Sulfonamides: A consistent trend across all five sulfonamide antibiotics (sulfamethazine,

291 sulfapyridine, sulfadiazine, sulfamethoxazole and sulfathiazole) was confirmed by hierarchical

292 clustering (Figure 2, Table 1). With a slight, but continuous decrease along the SRT gradient in both

293 Exp1 and Exp2, overlaid with a maximal $k_{\text {bio }}$ at 7 d SRT in Exp1, the sulfonamides show a dependence

294 on SRT that is distinctly different from all other substances. For all five investigated sulfonamides,

295 TPs related to the recently described pterin-sulfonamide conjugation pathway were predominantly

296 detected. ${ }^{49}$ This transformation pathway, presumably initiated by the enzyme dihydropteroate synthase

297 (DHPS), is related to the folate synthesis pathway that is ubiquitously present in bacteria and linked to

298 bacterial growth. Since the TSS-normalized heterotrophic activity is expected to be slightly decreasing

299 with higher SRTs due to the presence of more slow-growing organisms, ${ }^{15,35}$ this hypothesis is

300 consistent with the negative trend of both sulfonamide biotransformation rate constants and TSSnormalized oxygen uptake rates (OUR) with SRT (see Tables S4 and S5). The reason for the increased OUR and biotransformation rate constants in Exp1 at $7 \mathrm{~d}$ SRT is not known. As expected, neither inhibition by ATU or OCT nor oxygen limited conditions affected sulfonamide biotransformation. The previously reported sulfamethoxazole cleavage product 3-amino-5-methylisoxazole was not detected. ${ }^{51}$

Acetanilides: The acetanilides alachlor, dimethenamid, flufenacet, metolachlor and propachlor generally showed consistent, increasing trends with SRT. Yet, except for flufenacet $\left(k_{\max } / k_{\min }>5\right)$, which holds an oxyacetanilide moiety rather than a chloroacetanilide moiety, the acetanilides generally showed relatively small differences across the reactors $\left(k_{\max } / k_{\min } 1.28-2.32\right)$. From soil degradation studies, the major known biotransformation pathway for acetanilides is initial glutathioneS-transferase (GST)-mediated conjugation followed by further transformation to the corresponding

312 oxanilic acid (OXA) and ethanesulfonic acid (ESA) transformation products. ${ }^{52}$ In this study, TPs related to this pathway were detected for all investigated acetanilides. The GST system is a defense system ubiquitously present in plants, bacteria and animals. Our observation of only slight dependence

315 of $k_{\text {bio }}$ on SRT thus seems plausible given the expectation that, even if the microbial community composition changes with SRT, most microbes present should be able to catalyze this transformation. 
observed (Table 1). Consistent with the suggested dominance of the GST-mediated biotransformation pathway, all five acetanilides showed little dependence of $k_{\text {bio }}$ on oxygen limited conditions $\left(k_{\text {anaer }} / k_{\text {aer }}\right.$ : $0.67-0.92)$ or inhibition by ATU or OCT $\left(k_{\mathrm{inh}} / k_{\mathrm{cntrl}}>0.7\right)$.

Nitriles: For bromoxynil and acetamiprid, transformation of the nitrile to the corresponding amide was confirmed in the TP analysis, whereas the suspected further reaction of the amide to the carboxylic acid was not detected. Both MPs showed comparable increasing trends and a positive correlation of their rate constants with SRT (Figure 2, Table 1). Whereas nitrilases typically catalyze the reaction of nitriles to carboxylic acids, biotransformation by nitrile hydratase enzymes would explain the formation of the observed amides. ${ }^{53,54}$ Unlike bromoxynil, acetamiprid showed inhibition by ATU and OCT and a stronger dependence on aerobic conditions, which could indicate that an additional, presumably oxidative pathway (not detected) was present.

Esters: As observed earlier, ${ }^{10}$ the two esters trinexepac-ethyl and azoxystrobin showed different patterns although carboxylic acid TPs, suggesting an ester hydrolysis reaction, were detected for both MPs (Table 1). Most recently, it was demonstrated that, in activated sludge, azoxystrobin seemed to be nearly exclusively transformed by protozoan hydrolases ${ }^{54}$ and protozoa composition is indeed expected to depend on SRT. ${ }^{56,57}$ In our study, a strongly increased rate constant for azoxystrobin in the 7 d SRT reactors was observed in Exp1 and Exp2 (Figure 2). In contrast, no strong trends along SRT was observed for trinexapac-ethyl, which is consistent with the fact that no effect of protozoa inhibition was detected for trinexapac-ethyl ${ }^{55}$, and suggests that its hydrolysis is catalyzed by other enzymes, e.g., esterases, that are widely present in bacteria. ${ }^{57}$

Primary and secondary amides: For the three primary amides atenolol, levetiracetam and rufinamide, formation of the corresponding carboxylic acid, presumably via a hydrolysis reaction, was observed. Whereas the aliphatic amides atenolol and levetiracetam showed a very similar trend and low $k_{\max } / k_{\min }$ ratios $(<2)$ across SRTs, rufinamide, which contains an aromatic, more sterically hindered primary amide group, showed a strong positive correlation with SRT ( $\rho: 0.9-1.0$ and $\left.k_{\max } / k_{\min }: 4.5-15.8\right)$. Generally, amidohydrolases are widespread amongst bacteria ${ }^{58}$, supporting the observation for atenolol and levetiracetam that the reaction readily occurs at different SRTs. In 
contrast, rufinamide hydrolysis seems to rely on more specific enzymes that show a strongly increasing abundance with higher SRT.

As atenolol and levetiracetam, the secondary amides bezafibrate, fenhexamid and amisulpride did not reveal strong relationships with SRT. For bezafibrate, the detected TPs suggest that both amide hydrolysis and N-dealkylation occurred, whereas for fenhexamid the predicted hydrolysis was not observed. For amisulpride, TPs corresponding to N-oxidation and amine dealkylation were detected.

Tertiary Amides: For the tertiary amides valsartan, DEET, BEclB and MMclB low $k_{\text {anaer }} / k_{\text {aer }}$ ratios $(<0.35)$ suggest that mainly oxidative reactions are relevant. However, no consistent trends and reactions were observed. It has earlier been observed that tertiary amide dealkylation (except for valsartan) was relatively slow, ${ }^{36}$ explaining why many tertiary amides were not biotransformed fast enough to allow for a comparison of $k_{\text {bio }}$ here (Table S5). Similarly, this may explain why for the acetanilides, which are also tertiary amides, amide dealkylation was not the preferred pathway. Possibly, also for DEET and BEclB, other reactions might outcompete N-dealkylation, potentially explaining the different trend in $k_{\text {bio. }}$.

Phenylureas: Chlortoluron and diuron were investigated in both Exp1 and Exp2 and are clustered together (Figure 2). Both showed an increase in $k_{\text {bio }}$ with SRT, pronounced $k_{\max } / k_{\min }$ values (3.2-6.5) and small values of $k_{\text {anaer }} / k_{\text {aer }}$ ratios $(<0.15)$. In Exp2, isoproturon and metoxuron were additionally investigated. For both MPs, $k_{\text {bio }}$ increased with SRT and $k_{\text {anaer }} / k_{\text {aer }}$ ratios of $<0.13$ (isoproturon) and 0.36 (metoxuron) were observed. As chlortoluron and diuron, metoxuron showed the highest $k_{\text {bio }}$ at 15 d SRT. Demethylation at the urea-N was observed for all four phenylureas. Additionally, dihydroxylated transformation products were detected for diuron, chlortoluron and metoxuron and oxidation of a benzyl group to a carboxylic acid group was observed for isoproturon and chlortoluron.

367 Likely, differences in observed trends are therefore caused by a different relative importance of the 368 detected pathways.

Thioethers: The triazines irgarol and terbutryn (only investigated in Exp2) showed a similar trend with highest $k_{\mathrm{bio}}$ at 7 and $10 \mathrm{~d}$ SRT, strongly resembling the trend observed for ranitidine in Exp2 
(Figure 2). For all three MPs, the S-oxide TP was the major metabolite detected as described

372 previously for irgarol and terbutryn. ${ }^{44}$ Additionally, the biotransformation of all three MPs is affected to a similar degree by inhibition with ATU $\left(k_{\text {inh }} / k_{\text {cntrl }} 0.22-0.45\right)$, while only weak inhibition by OCT was found $\left(k_{\text {inh }} / k_{\text {cntrl }} 0.68-0.74\right)$, and all $k_{\text {bio }}$ values were considerably smaller under anaerobic conditions $\left(k_{\text {anaer }} / k_{\text {aer }}<0.33\right)$. The observation of this characteristic trend, together with the detected TPs, may therefore provide a hint that these three MPs are biotransformed by the same or related enzymes, most likely a specific type of a monooxygenase.

MPs with particularly strong positive dependence on SRT: For several MPs, high Spearman rank correlation coefficients were observed together with high $k_{\max } / k_{\min }$ ratios (Table 1). The five MPs with both $\rho>0.9$ and $k_{\max } / k_{\min }>10$ in at least one of the two experiments are acesulfame, ketoprofen, clofibric acid, gemfibrozil, and rufinamide. The artificial sweetener acesulfame is present in high concentrations in wastewater and has previously been suggested as stable tracer substance. ${ }^{59}$ However, more recently, it has been found that acesulfame was degraded by activated sludge communities from different WWTPs. ${ }^{50,60,61}$ Castronovo et al. observed quantitative biotransformation of acesulfame to sulfamic acid and a metabolic degradation was hypothesized but the reaction pathway is not entirely understood yet. ${ }^{60} \mathrm{We}$ are not aware of any previous studies having demonstrated the observed dependence of acesulfame biotransformation on SRT. For ketoprofen, clofibric acid and gemfibrozil, higher removal percentages were observed in an MBR system operated at $80 \mathrm{~d}$ compared to $20 \mathrm{~d}$ SRT. ${ }^{15}$ In the case of ketoprofen, higher biotransformation rate constants for nitrifying sludges (from WWTPs operated at higher SRTs) compared to non-nitrifying sludges were observed by Falås et al. ${ }^{23}$ Since in their study and also here no strong inhibitory effect of ATU was observed, a causal relationship with nitrification again seems unlikely.

Overall, a rather weak or even negative dependence on SRT was observed for many substitution-type transformations. In contrast, most oxidative transformations displayed clear trends of increasing degradation with SRT and often high $k_{\max } / k_{\min }$ ratios (Table 1, also see Figure S6 in the SI showing the relationship between $\log \left(k_{\text {anaer }} / k_{\text {aer }}\right)$ and $\left.\rho \times \log \left(k_{\min } / k_{\text {max }}\right)\right)$. Also, at least three out of the five chemicals showing strong correlations with SRT underwent oxidative transformations. Since microbial 
community composition and function can be expected to change with SRT, ${ }^{62}$ our findings suggest that 399 the observed substitution reactions are less dependent on these changes than the oxidative transformation reactions observed. Indeed, many of the observed substitutions are plausibly catalyzed by common enzymes involved in central metabolism or general defense mechanisms (e.g., GST, DHPS, esterases, peptidases). In contrast, the observed oxidative transformations are mostly expected to be catalyzed by oxidoreductases such as monooxygenases, which are known to be rarer (i.e., less generally widespread amongst different bacterial species ${ }^{58}$ ) and highly differentially expressed. The strong dependence of oxidative biotransformation reactions on SRT thus suggests that certain enzymes like monooxygenases either become more abundant or diverse at higher SRTs.

Generally, mainly two hypotheses have previously been discussed for increasing biomass-normalized MP biotransformation rate constants with increasing SRT: (1) Higher SRTs might allow slow-growing bacteria to establish stable populations, leading to increased metabolic capacity at higher SRTs (e.g, ${ }^{15}$, ${ }^{63}$ ). (2) The changed nutrient availabilities (lower food to microorganisms ratio) at higher SRTs may cause changes in enzyme expression patterns (e.g, ${ }^{15}, 16,62$ ). Also, both mechanisms have been hypothesized to lead to a higher taxonomic and/or functional diversity, which had been associated with increased MP removal earlier. ${ }^{58,64}$

414 With respect to hypothesis (1), one prominent explanation for higher MP biotransformation rates at higher SRTs is the increased presence of nitrifying microorganisms that are only able to grow above a certain threshold of SRT. Nitrifying bacteria, and, in particular, the enzyme ammonia monooxygenase

417 (AMO), have previously been associated with micropollutant biotransformation. ${ }^{10,}{ }^{65-69}$ In fact, in our 418 study, the increase in nitrifying activity in the range between 1 and $7 \mathrm{~d}$ SRT (Tables S4 and S5) 419 coincided with the strongest increase in mean MP biotransformation rates. However, the biotransformation of many MPs that exhibited increasing trends were not or only slightly affected by inhibitors of nitrifying activity (e.g., acesulfame, ketoprofen, gemfibrozil or rufinamide in Table 1), suggesting that AMO is likely not the primary driver of increased biotransformation rate constants at 423 higher SRTs for the majority of substances studied. With respect to hypothesis (1) another interesting 424 observation was that there were barely any obvious outliers in the trends (i.e., intermediate SRTs at 
which the $k_{\text {bio }}$ values of individual substances showed distinct peaks, see Figures S2 and S3). If specific metabolic pathways of specific key species were responsible for certain transformation reactions, fluctuations in their abundance would translate into fluctuations in biotransformation rates. Therefore, in our study either the abundance of the involved key species is very stable and does, for many MPs, predominantly depend on the SRT, or, what we consider more likely, the biotransformation of most MPs is less dependent on individual species but is rather achieved by a range of microorganisms and enzymes as hypothesized by de Lorenzo. ${ }^{70}$

Regarding hypothesis (2), in parallel to the observed positive trends for most oxidations, we observed decreasing trends for concentrations of effluent chemical oxygen demand (COD) towards higher SRTs (Table S3). Since higher cytochrome P450 enzyme expression has been observed under conditions with lower availability of easily degradable carbon, ${ }^{71}$ and because many cytochrome P450 enzymes can transform a broad range of substrates, these observations support hypothesis (2).

A few MPs, however, showed exceptional patterns. The sweetener acesulfame was not only the MP with by far the highest influent concentrations $(>50 \mu \mathrm{g} / \mathrm{L})$, but it also showed extraordinarily high $k_{\max } / k_{\min }$ ratios (Exp1: 74.0, Exp2: 23.7), supporting the hypothesis of a very specific (and possibly growth-related) pathway. ${ }^{60,}{ }^{61}$ Specific pathways were also suggested for two more of the five substances showing strongest positive dependence on SRT, i.e., gemfibrozil ${ }^{47}$ and ketoprofen. ${ }^{46}$ Azoxystrobin was the only MP that showed high $k_{\max } / k_{\min }$ ratios (Exp1: 22.9, Exp2: 6.7) but low correlation with SRT because of an outstanding maximum at intermediate SRTs. As discussed above, this MP might be transformed by specific protozoan species with a high abundance in the $7 \mathrm{~d}$ SRT reactor.

\section{Implications}

447 In this study, we demonstrated a clear increase in average biomass-normalized biotransformation rate constants with increasing SRT across an extensive list of MPs, independent of any effects caused by increased biomass concentrations or hydraulic retention times. ${ }^{22}$ The fact that not only average rates but also many individual trends showed pronounced positive relationships, revealed a clear direct influence of SRT on micropollutant biotransformation. If, in specific wastewaters, individual MPs 
whose biotransformation rates strongly benefit from high SRTs are of particular concern (e.g., for toxicological reasons or due to an industrial point source), operation at higher SRTs may thus provide a cost-effective solution to remove those MPs. Because we could further show that the strong observed increase from 3 to $10 \mathrm{~d}$ SRTs is not solely linked to the nitrifying activity, our results suggest that micropollutant removal may also benefit from increased SRTs in wastewater treatment situations in which nitrification is hindered, for instance under low temperature conditions ${ }^{25}$, 72 or high BOD loadings. ${ }^{73}$ However, the fact that for a number of MPs (e.g., the class of sulfonamide antibiotics) their rate constants did not increase with increasing SRTs (or remained below detectable limits under all SRTs tested), supports previous reports stating that a complete removal of micropollutants in domestic wastewaters likely cannot be achieved with biological treatment solutions alone. ${ }^{32}$

While we noted a large diversity of different trends with SRT for individual compounds, emphasizing the general complexity of the relationship between SRT and biotransformation rate constants, remarkable similarities in biotransformation patterns were observed for MPs undergoing similar transformations (e.g., sulfonamides, thioethers, nitriles, phenylureas). This does not only imply that transformation product and pathway analysis is beneficial for the understanding of how operational parameters affect micropollutant removal, but it may also help to obtain a more thorough understanding of biotransformation in complex microbial communities in general. Biotransformation of micropollutants present at low concentrations in mixed microbial communities is poorly understood at the level of involved enzymes and/or microorganisms. One promising approach to start elucidating these relationships may be to mine for associations between rate constants and the abundance of enzymes, enzyme-encoding genes or gene transcripts. ${ }^{74}$ Compared to results from pure culture experiments whose relevance to mixed communities has been questioned ${ }^{74}$ this approach allows to study biotransformation without strongly interfering with the system. Our results support the future application of such an approach in two ways: First, classification of substances according to their main transformation reaction type allows to specifically search for associations of rates with the abundance of enzymes (or the encoding genes or gene transcripts) that are known to catalyze the observed type of biotransformation reaction and to thus reduce false positive correlations. ${ }^{74}$ Second, the fact that micropollutants with shared functional groups indeed showed similarities in observed reactions and 
trends supports the validity of the underlying hypothesis of association mining, i.e., that similar

481 transformation reactions of different micropollutants are catalyzed by the same (group of) enzyme(s).

482 Finally, if micropollutants with similar functional groups can indeed be expected to be biotransformed 483 by the same enzyme systems, this should also facilitate prediction of transformation rates based on 484 molecular structure and community functional information in the future.

\section{Acknowledgement}

486 We thank Heinz Singer, Dr. David R. Johnson, Dr. Rebekka Gulde and Andreas Scheidegger (Eawag) 487 for fruitful discussions. Valérie Waser and Helene Wiesinger (Eawag) are acknowledged for assisting 488 with data analysis. We acknowledge financial support from the European Research Council under the 489 European Union's Seventh Framework Programme (ERC grant agreement no. 614768, PROduCTS) and from the Swiss National Science Foundation (SNF project number CR23I2_140698).

\section{Supporting Information}

492 Details on reactor operation; details on biotransformation experiments including details on mass 493 spectrometric analysis; supplementary results from biotransformation experiments including rate constants obtained in Exp1, Exp2 and ExpOx; detailed results from transformation product analysis. 


\section{References}

497 1. Ternes, T.; Joss, A., Human pharmaceuticals, hormones and fragrances. IWA publishing:

6. Luo, Y.; Guo, W.; Ngo, H. H.; Nghiem, L. D.; Hai, F. I.; Zhang, J.; Liang, S.; Wang, X. C., A review on the occurrence of micropollutants in the aquatic environment and their fate and removal during wastewater treatment. Sci. Total Environ. 2014, 473-474, 619-641.

7. Oulton, R. L.; Kohn, T.; Cwiertny, D. M., Pharmaceuticals and personal care products in effluent matrices: a survey of transformation and removal during wastewater treatment and implications for wastewater management. J. Environ. Monit. 2010, 12, 1956-1978.

8. Verlicchi, P.; Al Aukidy, M.; Zambello, E., Occurrence of pharmaceutical compounds in urban wastewater: removal, mass load and environmental risk after a secondary treatment--a review. Sci. Total Environ. 2012, 429, 123-155.

9. Prasse, C.; Stalter, D.; Schulte-Oehlmann, U.; Oehlmann, J.; Ternes, T. A., Spoilt for choice: A critical review on the chemical and biological assessment of current wastewater treatment technologies. Water Res. 2015, 87, 237-270.

10. Helbling, D. E.; Johnson, D. R.; Honti, M.; Fenner, K., Micropollutant Biotransformation Kinetics Associate with WWTP Process Parameters and Microbial Community Characteristics. Environ. Sci. Technol. 2012, 46, 10579-10588.

11. Miege, C.; Choubert, J. M.; Ribeiro, L.; Eusebe, M.; Coquery, M., Removal efficiency of pharmaceuticals and personal care products with varying wastewater treatment processes and operating conditions - conception of a database and first results. Water Sci. Technol. 2008, 57, 49-56.

12. Clara, M.; Strenn, B.; Gans, O.; Martinez, E.; Kreuzinger, N.; Kroiss, H., Removal of selected pharmaceuticals, fragrances and endocrine disrupting compounds in a membrane bioreactor and conventional wastewater treatment plants. Water Res. 2005, 39, 4797-4807.

13. Göbel, A.; McArdell, C. S.; Joss, A.; Siegrist, H.; Giger, W., Fate of sulfonamides, macrolides, and trimethoprim in different wastewater treatment technologies. Sci. Total Environ. 2007, 372, 361-371.

14. Koh, Y. K.; Chiu, T. Y.; Boobis, A. R.; Scrimshaw, M. D.; Bagnall, J. P.; Soares, A.; Pollard, S.; Cartmell, E.; Lester, J. N., Influence of operating parameters on the biodegradation of steroid estrogens and nonylphenolic compounds during biological wastewater treatment processes. Environ. Sci. Technol. 2009, 43, 6646-6654.

15. Maeng, S. K.; Choi, B. G.; Lee, K. T.; Song, K. G., Influences of solid retention time, nitrification and microbial activity on the attenuation of pharmaceuticals and estrogens in membrane bioreactors. Water Res. 2013, 47, 3151-3162.

16. Polesel, F.; Andersen, H. R.; Trapp, S.; Plosz, B. G., Removal of Antibiotics in Biological Wastewater Treatment Systems-A Critical Assessment Using the Activated Sludge Modeling Framework for Xenobiotics (ASM-X). Environ. Sci. Technol. 2016, 50, 10316-10334.

17. Langford, K. H.; Scrimshaw, M. D.; Birkett, J. W.; Lester, J. N., Degradation of nonylphenolic surfactants in activated sludge batch tests. Water Res. 2005, 39, 870-876. 
18. Kim, S.; Eichhorn, P.; Jensen, J. N.; Weber, A. S.; Aga, D. S., Removal of antibiotics in wastewater: Effect of hydraulic and solid retention times on the fate of tetracycline in the activated sludge process. Environ. Sci. Technol. 2005, 39, 5816-5823.

19. Stasinakis, A. S.; Kordoutis, C. I.; Tsiouma, V. C.; Gatidou, G.; Thomaidis, N. S., Removal of selected endocrine disrupters in activated sludge systems: effect of sludge retention time on their sorption and biodegradation. Bioresour. Technol. 2010, 101, 2090-2095.

20. Kreuzinger, N.; Clara, M.; Strenn, B.; Kroiss, H., Relevance of the sludge retention time (SRT) as design criteria for wastewater treatment plants for the removal of endocrine disruptors and pharmaceuticals from wastewater. Water Sci. Technol. 2004, 50, 149-156.

21. Suarez, S.; Lema, J. M.; Omil, F., Removal of pharmaceutical and personal care products (PPCPs) under nitrifying and denitrifying conditions. Water Res. 2010, 44, 3214-3224.

22. Douziech, M.; Conesa, I. R.; Benitez-Lopez, A.; Franco, A.; Huijbregts, M.; van Zelm, R., Quantifying variability in removal efficiencies of chemicals in activated sludge wastewater treatment plants - a meta-analytical approach. Environ. Sci. Proc. Imp. 2018, 20, 171-182.

23. Falås, P.; Andersen, H. R.; Ledin, A.; La Cour Jansen, J., Impact of solid retention time and nitrification capacity on the ability of activated sludge to remove pharmaceuticals. Environ. Technol. 2012, 33, 865-872.

24. Gerrity, D.; Holady, J. C.; Mawhinney, D. B.; Quinones, O.; Trenholm, R. A.; Snyder, S. A., The effects of solids retention time in full-scale activated sludge basins on trace organic contaminant concentrations. Water Environ Res 2013, 85, 715-724.

25. Neyestani, M.; Dickenson, E.; McLain, J.; Obergh, V.; Quinones, O.; Rock, C.; Gerrity, D., Solids retention time, influent antibiotic concentrations, and temperature as selective pressures for antibiotic resistance in activated sludge systems. Environ. Sci.: Water Res. Technol. 2017, 3, 883-896.

26. Neyestani, M.; Dickenson, E.; McLain, J.; Robleto, E.; Rock, C.; Gerrity, D., Impacts of solids retention time on trace organic compound attenuation and bacterial resistance to trimethoprim and sulfamethoxazole. Chemosphere 2017, 182, 149-158.

27. Abegglen, C.; Joss, A.; McArdell, C. S.; Fink, G.; Schlusener, M. P.; Ternes, T. A.; Siegrist, H., The fate of selected micropollutants in a single-house MBR. Water Res. 2009, 43, 2036-2046.

28. Majewsky, M.; Gallé, T.; Yargeau, V.; Fischer, K., Active heterotrophic biomass and sludge retention time (SRT) as determining factors for biodegradation kinetics of pharmaceuticals in activated sludge. Bioresour. Technol. 2011, 102, 7415-7421.

29. Bernhard, M.; Müller, J.; Knepper, T. P., Biodegradation of persistent polar pollutants in wastewater: comparison of an optimised lab-scale membrane bioreactor and activated sludge treatment. Water Res. 2006, 40, 3419-3428.

30. Fernandez-Fontaina, E.; Pinho, I.; Carballa, M.; Omil, F.; Lema, J. M., Biodegradation kinetic constants and sorption coefficients of micropollutants in membrane bioreactors.

Biodegradation 2013, 24, 165-177.

31. Gaulke, L. S.; Strand, S. E.; Kalhorn, T. F.; Stensel, H. D., Estrogen Biodegradation Kinetics and Estrogenic Activity Reduction for Two Biological Wastewater Treatment Methods. Environ. Sci. Technol. 2009, 43, 7111-7116.

32. Vuono, D. C.; Regnery, J.; Li, D.; Jones, Z. L.; Holloway, R. W.; Drewes, J. E., rRNA Gene Expression of Abundant and Rare Activated-Sludge Microorganisms and Growth Rate Induced Micropollutant Removal. Environ. Sci. Technol. 2016, 50, 6299-6309.

33. Falås, P.; Wick, A.; Castronovo, S.; Habermacher, J.; Ternes, T. A.; Joss, A., Tracing the limits of organic micropollutant removal in biological wastewater treatment. Water Res. 2016, 95, 240-249.

34. Schwarzenbach, R. P.; Gschwend, P. M.; Imboden, D. M., Environmental organic chemistry. John Wiley \& Sons: 2005.

35. Joss, A.; Zabczynski, S.; Göbel, A.; Hoffmann, B.; Löffler, D.; McArdell, C. S.; Ternes, T. A.; Thomsen, A.; Siegrist, H., Biological degradation of pharmaceuticals in municipal wastewater treatment: proposing a classification scheme. Water Res. 2006, 40, 1686-1696. 
36. Helbling, D. E.; Hollender, J.; Kohler, H.-P. E.; Fenner, K., Structure-Based Interpretation of Biotransformation Pathways of Amide-Containing Compounds in Sludge-Seeded Bioreactors. Environ. Sci. Technol. 2010, 44, 6628-6635.

37. Gulde, R.; Helbling, D. E.; Scheidegger, A.; Fenner, K., pH-dependent biotransformation of ionizable organic micropollutants in activated sludge. Environ. Sci. Technol. 2014, 48, 1376013768.

38. Petrie, B.; McAdam, E. J.; Hassard, F.; Stephenson, T.; Lester, J. N.; Cartmell, E., Diagnostic investigation of steroid estrogen removal by activated sludge at varying solids retention time. Chemosphere 2014, 113, 101-108.

39. Suarez, S.; Reif, R.; Lema, J. M.; Omil, F., Mass balance of pharmaceutical and personal care products in a pilot-scale single-sludge system: influence of T, SRT and recirculation ratio. Chemosphere 2012, 89, 164-171.

40. van den Berg, R. A.; Hoefsloot, H. C.; Westerhuis, J. A.; Smilde, A. K.; van der Werf, M. J., Centering, scaling, and transformations: improving the biological information content of metabolomics data. BMC Genom. 2006, 7, 1.

41. Hellinga, C.; Schellen, A.; Mulder, J. W.; Van Loosdrecht, M.; Heijnen, J., The SHARON process: an innovative method for nitrogen removal from ammonium-rich waste water. Water Sci. Technol. 1998, 37, 135-142.

42. Gulde, R.; Meier, U.; Schymanski, E. L.; Kohler, H. P.; Helbling, D. E.; Derrer, S.; Rentsch, D.; Fenner, K., Systematic Exploration of Biotransformation Reactions of Amine-Containing Micropollutants in Activated Sludge. Environ. Sci. Technol. 2016, 50, 2908-2920.

43. Stasinakis, A. S.; Kotsifa, S.; Gatidou, G.; Mamais, D., Diuron biodegradation in activated sludge batch reactors under aerobic and anoxic conditions. Water Res. 2009, 43, 1471-1479.

44. Luft, A.; Wagner, M.; Ternes, T. A., Transformation of Biocides Irgarol and Terbutryn in the Biological Wastewater Treatment. Environ. Sci. Technol. 2013, 48, 244-254.

45. Kern, S.; Baumgartner, R.; Helbling, D. E.; Hollender, J.; Singer, H.; Loos, M. J.; Schwarzenbach, R. P.; Fenner, K., A tiered procedure for assessing the formation of biotransformation products of pharmaceuticals and biocides during activated sludge treatment. J. Environ. Monit. 2010, 12, 2100-2111.

46. Quintana, J. B.; Weiss, S.; Reemtsma, T., Pathways and metabolites of microbial degradation of selected acidic pharmaceutical and their occurrence in municipal wastewater treated by a membrane bioreactor. Water Res. 2005, 39, 2654-2664.

47. Kjeldal, H.; Zhou, N. A.; Wissenbach, D. K.; von Bergen, M.; Gough, H. L.; Nielsen, J. L., Genomic, Proteomic, and Metabolite Characterization of Gemfibrozil-Degrading Organism Bacillus sp. GeD10. Environ. Sci. Technol. 2016, 50, 744-755.

48. Helbling, D. E.; Hollender, J.; Kohler, H. P.; Singer, H.; Fenner, K., High-throughput identification of microbial transformation products of organic micropollutants. Environ. Sci. Technol. 2010, 44, 6621-6627.

49. Achermann, S.; Bianco, V.; Mansfeldt, C. B.; Vogler, B.; Kolvenbach, B. A.; Corvini, P. F. X.; Fenner, K., Biotransformation of Sulfonamide Antibiotics in Activated Sludge: The Formation of Pterin-Conjugates Leads to Sustained Risk. Environ. Sci. Technol. 2018, 52, 6265-6274.

50. Men, Y.; Achermann, S.; Helbling, D. E.; Johnson, D. R.; Fenner, K., Relative contribution of ammonia oxidizing bacteria and other members of nitrifying activated sludge communities to micropollutant biotransformation. Water Res. 2016, 109, 217-226.

51. Ricken, B.; Corvini, P. F. X.; Cichocka, D.; Parisi, M.; Lenz, M.; Wyss, D.; Martinez-Lavanchy, P. M.; Muller, J. A.; Shahgaldian, P.; Tulli, L. G.; Kohler, H. P. E.; Kolvenbach, B. A., ipsoHydroxylation and Subsequent Fragmentation: a Novel Microbial Strategy To Eliminate Sulfonamide Antibiotics. Appl. Environ. Microbiol. 2013, 79, 5550-5558.

52. Singh, B.; Singh, K., Microbial degradation of herbicides. Crit. Rev. Microbiol. 2016, 42, 245261.

53. Kobayashi, M.; Shimizu, S., Versatile Nitrilases - Nitrile-Hydrolyzing Enzymes. FEMS Microbiol. Lett. 1994, 120, 217-223. 
54. Vesela, A. B.; Pelantova, H.; Sulc, M.; Mackova, M.; Lovecka, P.; Thimova, M.; Pasquarelli, F.; Picmanova, M.; Patek, M.; Bhalla, T. C.; Martinkova, L., Biotransformation of benzonitrile herbicides via the nitrile hydratase-amidase pathway in rhodococci. J. Ind. Microbiol. Biotechnol. 2012, 39, 1811-1819.

55. Gulde, R.; Anliker, S.; Kohler, H. E.; Fenner, K., Ion Trapping of Amines in Protozoa: A Novel Removal Mechanism for Micropollutants in Activated Sludge. Environ. Sci. Technol. 2018, 52, 52-60.

56. Poole, J. E. P., A Study of the Relationship between the Mixed Liquor Fauna and Plant Performance for a Variety of Activated-Sludge Sewage-Treatment Works. Water Res. 1984, 18, 281-287.

57. Cech, J. S.; Hartman, P.; Macek, M., Bacteria and Protozoa Population-Dynamics in Biological Phosphate Removal Systems. Water Sci. Technol. 1994, 29, 109-117.

58. Johnson, D. R.; Helbling, D. E.; Lee, T. K.; Park, J.; Fenner, K.; Kohler, H. P. E.; Ackermann, M., Association of biodiversity with the rates of micropollutant biotransformations among fullscale wastewater treatment plant communities. Appl. Environ. Microbiol. 2015, 81, 666-675.

59. Loos, R.; Carvalho, R.; Antonio, D. C.; Comero, S.; Locoro, G.; Tavazzi, S.; Paracchini, B.; Ghiani, M.; Lettieri, T.; Blaha, L.; Jarosova, B.; Voorspoels, S.; Servaes, K.; Haglund, P.; Fick, J.; Lindberg, R. H.; Schwesig, D.; Gawlik, B. M., EU-wide monitoring survey on emerging polar organic contaminants in wastewater treatment plant effluents. Water Res. 2013, 47, 64756487.

60. Castronovo, S.; Wick, A.; Scheurer, M.; Nödler, K.; Schulz, M.; Ternes, T. A., Biodegradation of the artificial sweetener acesulfame in biological wastewater treatment and sandfilters. Water Res. 2017, 110, 342-353.

61. Kahl, S.; Kleinsteuber, S.; Nivala, J.; van Afferden, M.; Reemtsma, T., Emerging Biodegradation of the Previously Persistent Artificial Sweetener Acesulfame in Biological Wastewater Treatment. Environ. Sci. Technol. 2018, 52, 2717-2725.

62. Vuono, D. C.; Benecke, J.; Henkel, J.; Navidi, W. C.; Cath, T. Y.; Munakata-Marr, J.; Spear, J. R.; Drewes, J. E., Disturbance and temporal partitioning of the activated sludge metacommunity. ISME J. 2015, 9, 425-435.

63. Clara, M.; Kreuzinger, N.; Strenn, B.; Gans, O.; Kroiss, H., The solids retention time-a suitable design parameter to evaluate the capacity of wastewater treatment plants to remove micropollutants. Water Res. 2005, 39, 97-106.

64. Torresi, E.; Fowler, S. J.; Polesel, F.; Bester, K.; Andersen, H. R.; Smets, B. F.; Plosz, B. G.; Christensson, M., Biofilm Thickness Influences Biodiversity in Nitrifying MBBRs-Implications on Micropollutant Removal. Environ. Sci. Technol. 2016, 50, 9279-9288.

65. Fernandez-Fontaina, E.; Omil, F.; Lema, J. M.; Carballa, M., Influence of nitrifying conditions on the biodegradation and sorption of emerging micropollutants. Water Res. 2012, 46, 54345444.

66. Tran, N. H.; Urase, T.; Kusakabe, O., The characteristics of enriched nitrifier culture in the degradation of selected pharmaceutically active compounds. J. Hazard. Mater. 2009, 171, 1051-1057.

67. Yi, T.; Harper, W. F., The link between nitrification and biotransformation of $17 \alpha-$ ethinylestradiol. Environ. Sci. Technol. 2007, 41, 4311-4316.

68. Roh, H.; Subramanya, N.; Zhao, F.; Yu, C.-P.; Sandt, J.; Chu, K.-H., Biodegradation potential of wastewater micropollutants by ammonia-oxidizing bacteria. Chemosphere 2009, 77, 10841089.

69. Men, Y.; Han, P.; Helbling, D. E.; Jehmlich, N.; Herbold, C.; Gulde, R.; Onnis-Hayden, A.; Gu, A. Z.; Johnson, D. R.; Wagner, M.; Fenner, K., Biotransformation of Two Pharmaceuticals by the Ammonia-Oxidizing Archaeon Nitrososphaera gargensis. Environ. Sci. Technol. 2016, 50, $4682-4692$.

70. de Lorenzo, V., Systems biology approaches to bioremediation. Curr. Opin. Biotechnol. 2008, 19, 579-589. 
71. Drewes, J. E.; Li, D.; Regnery, J.; Alidina, M.; Wing, A.; Hoppe-Jones, C., Tuning the performance of a natural treatment process using metagenomics for improved trace organic chemical attenuation. Water Sci. Technol. 2014, 69, 628-633.

72. Huang, X.; Li, W.; Zhang, D.; Qin, W., Ammonium removal by a novel oligotrophic Acinetobacter sp. Y16 capable of heterotrophic nitrification-aerobic denitrification at low temperature. Bioresour. Technol. 2013, 146, 44-50.

73. Carrera, J.; Vicent, T.; Lafuente, J., Effect of influent COD/N ratio on biological nitrogen removal (BNR) from high-strength ammonium industrial wastewater. Process Biochem. 2004, 39, 2035-2041.

74. Johnson, D. R.; Helbling, D. E.; Men, Y.; Fenner, K., Can meta-omics help to establish causality between contaminant biotransformations and genes or gene products? Environ. Sci.: Water Res. Technol. 2015, 1, 272-278.

75. Dunbar, J.; White, S.; Forney, L., Genetic diversity through the looking glass: Effect of enrichment bias. Appl. Environ. Microbiol. 1997, 63, 1326-1331. 